Available online at Journal Website
https://ijma.journals.ekb.eg/
Main subject [General Surgery]

Original article

\title{
Role of Laparoscopy in Management of Doubt Cases of Acute Abdomen
}

Ahmed Abdelrahman Al-Sharkawy; Nagah Atwa Salem; Mohamed Elsayed Abo-Mera.

Department of General Surgery, Damietta Faculty of Medicine, Al-Azhar University, Egypt

Corresponding author: Ahmed Abdelrahman Al-Sharkawy.

Email: aammsharkos@domazhermedicine.edu.eg

Submission date: September 28, 2020; Revision date: March 26, 2021; Acceptance date: March 27, 2021

DOI: 10.21608/ijma.2021.44397.1183

DOAJ

\section{ABSTRACT}

Background: Acute abdomen is a surgical emergency, that needs early diagnosis and treatment to avoid complications and save patient life. However, accurate diagnosis is crucial to avoid unnecessary surgery. Laparoscopy could represent an optimal solution in these circumstances.

The aim of the work: To evaluate the role of laparoscopy in management of doubt cases of acute abdomen.

Patients and Methods: It is a prospective study, which held at Al-Azhar University Hospital [Damietta] during the first six months of 2020 and included 30 patients who presented by acute abdominal pain. All were evaluated by full history taking, clinical examination, laboratory and radiological investigations. Then, all underwent diagnostic laparoscopy, which had been continued to therapeutic laparoscopy, or converted to laparoscopy-assisted laparotomy at the same setting. Rate of success, operative diagnosis and postoperative complications were documented.

Results: The most common cause of acute abdomen was acute appendicitis [23.33\%] followed by acute cholecystitis [13.33\%], then perforated peptic ulcer [10.0\%]. Negative exploration had been reported in $10 \%$. Therapeutic laparoscopy was successful in [56.7\%] while [43.3\%] required conversion to laparotomy. Complications were observed in 14 patients [46.7\%] and wound infection is the most common [30.0\%]. Radiological investigations failed to elaborate diagnosis in 12 patients, and laparoscopy achieved the diagnosis in 9 [75.0\%] of them.

Conclusion: The laparoscopic approach in doubt acute abdomen is proved to be feasible and safe in experienced hands. It provides diagnostic accuracy as well as therapeutic capabilities. It reduces pain, improves recovery, shortens hospitalization and improves cosmetic results.

Keywords: Acute Abdomen; Doubt; Laparoscopy; Laparotomy; Appendicitis.

This is an open-access article registered under the Creative Commons, ShareAlike 4.0 International license [CC BY-SA 4.0] [https://creativecommons.org/licenses/by-sa/4.0/legalcode. 3 [2] April-June: 1405-1411. [DOI: 10.21608/ijma.2021.44397.1183].

* Main subject and any subcategories have been classified according to the research topic. 


\section{INTRODUCTION}

Abdominal pain is a common problem especially in children and females. Abdominal pain may be a simple thing or it may be a dangerous and life threatening one. Abdomen is a Pandora's Box. It is very difficult to come to a correct diagnosis. Acute appendicitis, perforation, ovarian torsion, ectopic pregnancy and rupture are some of the common abdominal emergencies which require immediate surgery. In this era of increasing medical litigation, the surgeon has to be very careful about his patient. It is mandatory to come to a correct diagnosis and to treat accordingly ${ }^{[1]}$.

Diagnostic laparoscopy gives many advantages in the management of many intra-abdominal conditions where the correct diagnosis could not establish clinically or even with the help of imaging studies [acute appendicitis, pelvic inflammatory disease, hollow viscus perforation, bowel ischemia, etc.] [2].

In most of the patients, the clinical signs and symptoms are masked by the treatments given by physicians at many hospitals at different stages of disease progression. Radiologists giving different reports of imaging studies and advising to correlate clinically. In these circumstances, diagnostic laparoscopy alone helps to solve the issue. Diagnostic laparoscopy reduces the number of negative laparotomies in acute abdomen and prevents severe peritonitis which may occur as a result of delay in diagnosis [3]. Diagnostic laparoscopy plays an important role in the evaluation of abdominal pain in young children. It has been studied and documented in many journals [4].

Mesenteric ischemia and subsequent bowel gangrene can better be controlled and managed reasonably if early diagnostic laparoscopy is advocated [5].

In acute abdominal emergency, early diagnosis enables early intervention before the development of complications. Clinical sense and laboratory investigations could provide a professional diagnosis. However, the need to reach a final diagnosis is crucial, and permits the proper intervention. Thus, looking inside by laparoscopy could represent an optimal solution with final diagnosis and surgical intervention at the same setting in indicated situations.

\section{AIM OF WORK}

The current study designed to evaluate the role of laparoscopy in management of doubt cases of acute abdomen, either encouragement or inhibition.

\section{PATIENTS AND METHODS}

The current study is a prospective study, which held at Al-Azhar University Hospital [Damietta] during 2020 and included patients who presented by acute abdominal pain. It included 30 patients.

Inclusion criteria were hemodynamic stability, signs and symptoms of acute abdominal pain of doubt diagnosis. On the other side, exclusion criteria were uncontrolled co-agulopathy hemodynamic instability, chronic abdominal pain, severe distended abdomen, and patients refusing diagnostic laparoscopy after routine investigations.

Preoperative data: included full medical history, general and local physical examination, laboratory and radiological investigations.

Operative Techniques [Figures 1-3]: Diagnostic laparoscopy was performed with proper care. The anaesthesia of choice was general, as it enables us to do therapeutic management after diagnosis. Prophylactic antibiotics were generally not indicated in diagnostic laparoscopy but in this study, two grams of the third generation cephalosporins were administered before the induction of anaesthesia and continued according to the findings. Ryle's tube was used to decompress the stomach and Foley's catheter to empty the urinary bladder. The patient's position was supine position. The head was tilted up or down by 15 degree depending on the main area of examination, with the availability of lithotomy position if needed. Elastic stokes [graduated compression stocks] on the legs during the operation were used to prevent thromboembolism. Pneumo-peritoneum was created using a direct access method. Intraabdominal pressure was kept initially 12 to $14 \mathrm{mmHg}$ which is reduced to $10 \mathrm{mmHg}$ after insertion of all trocars [First $10 \mathrm{~mm}$ trocar was put in supra-umbilical position and further trocars were inserted depending 
on the case. In addition, 30-degree and Zero-degree [KARL STORZ®] telescope was used. Non traumatic intestinal graspers were used to deal with the intestine and omentum. The observation had been carried out for all fluids [e.g., pus, bile, intestinal contents and blood]. Then aspiration and sampling.
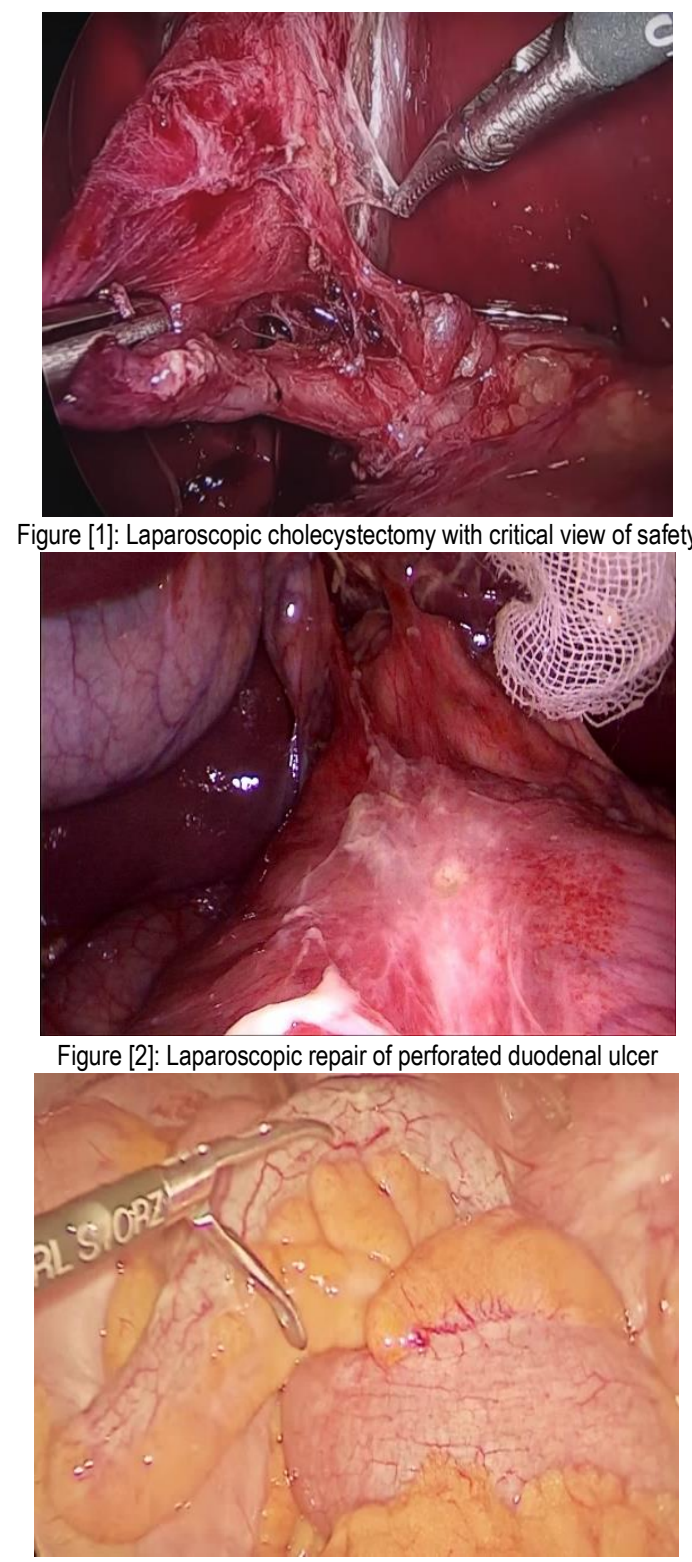

Figure [3]:Laparoscopic appendectomy

Searching for the cause: beginning with the most probable according to preoperative diagnosis and intraoperative finding [nature of the fluid, aggregation of loops or omental adhesions]. If there was a satisfactory cause, compatible along with the clinical data, exploration was completed and diagnostic laparoscopy was considered successful even if there is a negative exploration. Dealing with the cause laparoscopically was secondly tried either completed laparoscopically, laparoscopic assisted via planned incision according to pathology, or total conversion to open surgery. If there was doubtful or unsatisfactory cause, exploratory incision was done usually midline incision; upper or lower according to most probable diagnosis. Peritoneal toilet was usually done by suction irrigation; $5 \mathrm{~mm}$ laparoscopic suction cannula was used. Irrigation by the large amount of normal saline was done. Finally, drains were inserted according to pathology.

Postoperative follow up and Evaluation: Diagnostic value of laparoscopy in comparison with provisional diagnosis. Therapeutic role of laparoscopy in comparison with open surgery. General and local complications related to laparoscopy. The next figures represented laparoscopic findings some patients.

\section{RESULTS}

Female patients of acute abdomen were slightly more than that of male patients [Table 1]. The most common age groups were the third and fifth decades [26.67\% for each decade] followed by the fourth and sixth decades [23.33\% for each] [Table 1].

The most common cause of acute abdomen in this study was acute appendicitis [23.33\%] followed by acute cholecystitis [13.33\%], then perforated peptic ulcer [10.0\%]. Negative exploration had been reported in $10 \%$ [Table 2].

Laparoscopy was done in all cases [100\%]; therapeutic laparoscopy was successful in 17 cases [56.7\%] while 13 [43.3\%] patients required to be converted to laparotomy [Table 3].

Complications related to laparoscopy in our study were observed in 14 out of 30 cases [46.7\%]; with wound infection is the most common one [30.0\%] [Table 4].

The diagnosis which wasn't reached by radiological investigations in 12 [40\%] cases were achieved by Laparoscopy in 9 [75\%] cases of them [Table 5]. 


\begin{tabular}{|l|l|c|}
\hline \multicolumn{3}{c}{ Table [1]: Patient and characteristics and laparoscopy-detected pathology } \\
\hline Variable & Female & Statistics \\
\cline { 2 - 3 } & Male & $16[53.3 \%]$ \\
\hline \multirow{3}{*}{ Age group } & {$[21-30]$} & $14[46.67 \%]$ \\
\cline { 2 - 3 } & {$[31-40]$} & $8[26.67 \%]$ \\
\cline { 2 - 3 } & {$[41-50]$} & $7[23.33 \%]$ \\
\cline { 2 - 3 } & {$[51-60]$} & $8[26.67 \%]$ \\
\hline
\end{tabular}

Table [2]: Laparoscopically detected pathology among studied patients

\begin{tabular}{|l|c|c|}
\hline \multicolumn{1}{|c|}{ Pathology } & No. of cases & Percentage [\%] \\
\hline Acute appendicitis & 7 & $23.33 \%$ \\
\hline Acute cholecystitis & 4 & $13.33 \%$ \\
\hline Perforated peptic ulcer & 3 & $10.0 \%$ \\
\hline negative exploration & 3 & $10.0 \%$ \\
\hline Rupture ovarian cyst & 2 & $6.67 \%$ \\
\hline Acute diverticulitis & 2 & $6.67 \%$ \\
\hline Adhesive Intestinal obstruction & 2 & $6.67 \%$ \\
\hline GIT malignancy & 2 & $6.67 \%$ \\
\hline Rupture ectopic pregnancy & 1 & $3.33 \%$ \\
\hline Meckel's diverticulum & 1 & $3.33 \%$ \\
\hline Mesenteric vascular occlusion & 1 & $3.33 \%$ \\
\hline Acute pancreatitis & 1 & $3.33 \%$ \\
\hline Inflammatory bowel disease & 1 & $3.33 \%$ \\
\hline
\end{tabular}

Table [3]: Management among studied patients

\begin{tabular}{|l|c|c|}
\hline Management & No. of cases & Percentage \\
\hline Therapeutic laparoscopy & 17 & $56.67 \%$ \\
\hline laparotomy [conversion] & 13 & $43.33 \%$ \\
\hline Total & 30 & $100.00 \%$ \\
\hline
\end{tabular}

Table [4]: Complications among studied patients

\begin{tabular}{|l|c|c|}
\hline Complications & No. of cases & Percentage of all cases \\
\hline Wound infection & 9 & $30 \%$ \\
\hline Shoulder pain & 4 & $13 \%$ \\
\hline Systemic complications & 4 & $13 \%$ \\
\hline Port site hernia & 3 & $10 \%$ \\
\hline Subcutaneous emphysema & 2 & $7 \%$ \\
\hline Bowel injury & 2 & $7 \%$ \\
\hline Total complications & 14 & $46.7 \%$ \\
\hline Uncomplicated & 16 & $53.3 \%$ \\
\hline
\end{tabular}

Table [5]: Radiological investigations and laparoscopy findings regarding the diagnosis of acute abdomen

\begin{tabular}{|l|l|l|}
\hline DIAGNOSIS & Radiological & Laparoscopy \\
\hline Correct & $18[60 \%]$ & $27[90 \%]$ \\
\hline Incorrect [negative] & $12[40 \%]$ & $3[10 \%]$ \\
\hline
\end{tabular}

\section{DISCUSSION}

This study investigated the role of laparoscopy in doubt cases of acute abdomen. It included 30 patients of acute abdomen who presented to Al-Azhar University Hospitals for emergency management. In the current work, there is slight increase of females [53.3\%] due to the increased number of cases of acute cholecystitis in females and gynecological conditions. Al-Tai [6] reported an equal distribution between the two genders in the acute abdomen [male/female ratio 1:1]. However, Hagos [7] reported a male gender predominance [M:F ratio 4.1: 1]. Otherwise, Ram and Chandana [8] and Hackenberg et al. [9] also reported that, acute abdomen is distributed equally between both sexes and more common in the reproductive age group [15-45 years]. 
Results of laparoscopy revealed that, acute appendicitis was the most common cause of acute abdomen [23.3\%] followed by acute cholecystitis [13.3\%].

Subramaniam [1] reported acute appendicitis as the most common cause of acute abdomen [79.0\%; high percentage than the current work], followed by perforated peritonitis [ $9.0 \%$ [ $7 \%$ duodenal \& $2 \%$ ileal]].

Al-Tai [6] reported that, the most common cause of acute abdomen was acute appendicitis in [50\%] of cases [which comparable to the current work].

Melkunde et al. [10] reported that, the commonest three diagnoses of acute abdomen were acute appendicitis [45\%], acute cholecystitis [20\%] and duodenal perforation [18\%].

Zarin et al. [11] reported that, the most common diagnosis was acute appendicitis [69\%] then duodenal perforation [6.6\%].

In this study, 2 cases [6.67\%] presented as GIT malignancy, 1 case [3.3\%] with inflamed Meckel's diverticulum and 1 case [6.7\%] of mesenteric vascular occlusion. All these findings were missed on radiological investigations, but were diagnosed accurately on laparoscopy. So diagnostic accuracy of radiological investigations was $60.0 \%$ [18 out of 30 cases] while the same for laparoscopy was $90.0 \%$ [ 27 out of 30 cases]. Subramaniam [1] reported that, laparoscopy was able to diagnose $7.0 \%$ over the radiological work up in acute abdomen [e.g., mesenteric ischemia, ectopic pregnancy, twisted ovarian cyst and ileal perforation].

In the current work, the total laparoscopic management was possible in 17 cases [56.7\%] while laparotomy conversion was done in 13 cases [43.3\%], such as mesenteric ischemia, Meckel's diverticulum and GIT malignancy. Melkunde et al. [10] reported a laparotomy conversion rate of $11 \%$ of cases, which is lower than the current work. The causes of conversion in their work were intestinal injury, gangrenous appendix or didn't have definitive diagnosis.

Subramaniam [1] reported a conversion rate to midline laparotomy of $22 \%$. The causes were mesenteric ischemia, ectopic pregnancy and ileocecal tuberculosis. Zarin et al. [11] had $11.6 \%$ rate of conversion mostly due to intestinal injury. The causes of high conversion rate in the current work are the lack of specific laparoscopic equipment's and uncontrolled bleeding.

In this study, complications were seen in 14 cases [46.7\%], 9 cases [30\%] had wound infection which were treated accordingly, 4 cases [13\%] had shoulder pain and systemic complications such as pulmonary embolism. Bowel injury and subcutaneous emphysema cases were 2 cases [ $7 \%$ for each].

Melkunde et al. [10] reported a complication rate of $13 \%$ mostly due to wound infection.

Nielsen et al. [12] reported $14.0 \%$ complication rate in the laparoscopically completed diagnostic and therapeutic approaches, that increased to $19 \%$ in the converted group.

Byrne et al. [13] reported a complication rate $27.7 \%$ in the laparoscopic group and $43.6 \%$ in the open group, while Zimmermann et al. [14] reported a complication rate of $20 \%$ in the laparoscopically completed group and $30 \%$ in the converted group. The variability in complication rate could be attributed to difference in operator experience, encountered pathology and different samples between studies.

Overall, Melkunde et al. [10] recommended wide use of laparoscopy for acute abdomen, with high diagnostic accuracy [up to $80-99 \%$ ]. Specifically, with unclear abdominal symptoms and those cases where the exact diagnosis of presentation is difficult. Diagnostic laparoscopy can change the initial clinical diagnosis and help in planning the treatment of emergency cases. In addition, Bhandari et al. [15] compared laparoscopy to open surgery. They reported that, laparoscopic surgery has more benefits due to short hospital stay, less blood loss, reduced operative duration, faster recovery, reduce postoperative edema, reduce surgical indication levels like inflammatory and stress responses to surgery. On the other side, the length of incision of open surgery was much longer than that of laparoscopic surgery.

Al-Tai [6] investigated laparoscopy in acute abdomen and reported that, laparoscopy gives a superior inspection of the abdomen with a low risk of 
injury to the tissues. They reported a low rate of conversion to open surgery in difficult and nonprogressed and long surgeries. In these situations, the incision for open surgery was guided by the findings of laparoscopy. In addition they reported low complications associated with laparoscopy and stated that these complications can be minimized further by using the mini-laparotomy technique. Diagnostic laparoscopy decreases overall hospital stay postoperative complications including pain early mobilization and avoid big scars. Ram and Chandana [8] reported that, diagnostic laparoscopy for the acute abdomen provides a superior overview of the abdominal organs with minimal trauma. It permits the ability to do further surgeries if required [could be completed laparoscopic or laparoscopic-assisted open surgery]. The laparo-scopy-associated complications are few and can be further minimized. Therapeutic interventions followed diagnostic laparoscopy were appendicectomy, adhesinolysis, repair of peptic ulcer perforation. Diagnostic laparoscopy reduces overall hospital stay and postoperative complications.

Grundmann et al. [16] reported that, in the emergency department, the acute abdomen needs simultaneous rapid accurate diagnosis and treatment. Diagnostic laparoscopy permits direct vision of abdominal viscera and eliminates difficulties in diagnosis and treatment. The results are better in laparoscopic when compared to open laparotomy, as it permits early diagnosis, had reduced postoperative pain, shorter hospitalization, costs and cosmetic outcome. Furthermore, Subramaniam [1] concluded that, diagnostic followed by appropriate laparoscopic surgery must be the gold standard approach irrespective of the anatomical and pathological nature of causes of the acute abdomen. It decreases wrong treatments and thorough exploration of peritoneal cavity is possible. In addition, it had a small incision, small scar, low complications [e.g., wound infection, adhesions and incisional hernia] and less chance of infertility]. It had a sensitivity and specificity of $100 \%$. Kostov [17] concluded that, in an acute abdomen of non-traumatic causes, laparoscopy elucidated a diagnosis in a large number of cases and is a very good diagnostic and therapeutic instrument. They recommend it as a first-line surgical investigation for undiagnosed acute abdomen.
Finally, Sharaf et al. ${ }^{[18]}$ concluded a study with 100 patients of the acute abdomen and divided them into patients with definite and doubt diagnosis before laparoscopy. They concluded that, laparoscopy for the acute abdomen is safe, feasible and effective, with minor trauma. It prevents extensive preoperative investigations or delay in treatment, and provided fast postoperative recovery with complications.

On the other side, Fowler [19] is against laparoscopic surgery due to effects of $\mathrm{CO} 2$ pneumoperitoneum which adversely affected the ability of peritoneum to prevent bacteremia and endotoxemia. Additionally, the morphology of mesothelium was altered by $\mathrm{CO}_{2}$ pneumoperitoneum. Also, $\mathrm{CO}_{2}$ depresses the cytokine release by macrophages reducing the efficiency of the response to the insult. Hanly et al. [20] reported that, $\mathrm{CO}_{2}$ pneumoperitoneum may promote the persistence of infection, increase the risk of recurrent abdominal infection and increase bacterial counts of E.coli and B.fragilis.

Fowler [19] and Lee et al. [21] differentiated between sick and fit patients, mild or severe disease for laparoscopy and reported that, laparoscopy is suitable, effective and safe for the diagnosis and treatment of the acute abdomen for "selected patients". For example, failure rates for laparoscopic repair of perforated peptic ulcer are higher with increased severity of illness, as assessed by the APACHE II score.

Conclusion: The laparoscopic approach in the doubt acute abdomen is proved to be feasible and safe in experienced hands. It provides diagnostic accuracy as well as therapeutic capabilities. Sparing patient's laparotomy reduces postoperative pain, improves recovery of gastrointestinal [GI] function, reduces hospitalization, and improves cosmetic results. This is a promising approach to play a significant role in emergency abdominal situations and will certainly become increasingly important in today's health care environment.

Financial and Non-financial Relationships and Activities of Interest

None 


\section{REFERENCES}

1. Subramaniam R. Diagnostic laparoscopy in acute abdominal pain. Int Surg J 2019;6:1104-7. [DOI: 10.18203/23492902.isj20191029].

2. Ning N, Xia SY, Ma B, Li R, DU XH. [Application of laparoscopic technique in acute abdomen of gastrointestinal surgery]. Zhonghua Wei Chang Wai Ke Za Zhi. 2013 Oct; 16 [10]:960-2. Chinese [English Abstract]. [PMID: 24158868].

3. Navez B, Navez J. Laparoscopy in the acute abdomen. Best Pract Res Clin Gastroenterol. 2014 Feb; 28 [1]: 3-17. [DOI: 10.1016/j.bpg.2013.11.006].

4. Jimenez Rodriguez RM, Segura-Sampedro JJ, Flores-Cortés M, López-Bernal F, Martín C, Diaz VP, Ciuro FP, Ruiz JP. Laparoscopic approach in gastrointestinal emergencies. World J Gastroenterol. 2016 Mar 7; 22 [9]: 2701-10. [DOI: 10.3748/wjg.v22.i9.2701].

5. Agrusa A, Romano G, Di Buono G, Dafnomili A, Gulotta G. Laparoscopic approach in abdominal emergencies: a 5year experience at a single center. G Chir. 2012 NovDec; 33[11-12]:400-3. [PMID: 23140925].

6. Al-Tai AHA. Advantages of the laparoscopic approach in the management of acute abdomen in Karbala governorate, Iraq. Int. J. Res. Pharm. Sci. 2018; 10[1]: 650-653. [DOI: 10.26452/ijrps.v10i1.1896].

7. Hagos M. Acute abdomen in adults: A two-year experience in Ethiopia. Ethiopia Med J. 2015: 53 [1]: 19-24. [PMID: 26591288].

8. Ram K, Chandana S. A study of the role of diagnostic laparoscopy in 25 cases of acute abdomen. Int Surg J. 2017; 4 [8]: 2585-2588. [DOI: 10.18203/2349-2902. isj20173393]

9. Hackenberg T, Mentula P, Leppäniemi A, Sallinen V. Laparoscopic versus Open Surgery for Acute Adhesive Small-Bowel Obstruction: A Propensity Score-Matched Analysis. Scand J Surg. 2017 Mar; 106 [1]: 28-33. [DOI: 10.1177/ 1457496916641341]

10. Melkunde BD, Ranbagle PV, Sarfaraj Pathan. A clinical study of the role of laparoscopy in acute abdomen. Indian $\mathrm{J}$ Basic Applied Medl Res. 2018; 7 [4]: 5 - 10.

11. Zarin M, Zeb J, Khan MA, Maroof SA, Ibrar S. Acute abdomen; role of laparoscopy in acute abdomen. Professional Med J 2019; 26 [2]:438-442. [DOI:10.29309/ TPMJ/ 2019.26.03.3246].
12. Nielsen LBJ, Tengberg LT, Bay-Nielsen M. Laparoscopy in major abdominal emergency surgery seems to be a safe procedure. Dan Med J. 2017 May; 64 [5]: A5370. PMID: 28552093

13. Byrne J, Saleh F, Ambrosini L, Quereshy F, Jackson TD, Okrainec A. Laparoscopic versus open surgical management of adhesive small bowel obstruction: a comparison of outcomes. Surg Endosc. 2015 Sep; 29 [9]: 2525-32. [DOI: 10.1007/s00464-014-4015-7]

14. Zimmermann M, Hoffmann M, Laubert T, Jung C, Bruch HP, Schloericke E. Conversion of laparoscopic surgery for perforated peptic ulcer: a single-center study. Surg Today. 2015; 45[11]:1421-8. [DOI: 10.1007/s00595-0151112-8]

15. Bhandari V, Bhandari M. Compare the clinical and postoperative outcomes: laparoscopic versus open surgery. Int Surg J. 2020;7[3]:861-866. [DOI: 10.18203/ 2349-2902.isj20200834].

16. Grundmann RT, Petersen M, Lippert H, Meyer F. [The acute [surgical] abdomen - epidemiology, diagnosis and general principles of management]. Z Gastroenterol. 2010 Jun;48[6]:696-706. German [English abstract]. [DOI: 10. 1055/s-0029-1245303].

17. Kostov K. Specific features and capabilities of emergency laparoscopy in the acute non-traumatic abdomen. $\mathrm{J}$ of IMAB. 2019;25[4]: 2843-2846. [DOI: 10.5272/jimab. 2019254.2843].

18. Sharaf MF, Ghalwash ET, Ali AM. Role of Laparoscopy in Diagnosis and Treatment of Acute Abdominal Pain. EJHM 2020; 79: 442-445. [DOI: 10.21608/ejhm.2020. 80838]

19. Fowler DL. Laparoscopy in the Acute Abdomen. In: Assalia A., Gagner M., Schein M, [eds]. Controversies in Laparoscopic Surgery. Springer, Berlin, Heidelberg. 2006; Chapter 3: pp 45-51. [DOI: 10.1007/3-540-309640_7].

20. Hanly EJ, Mendoza-Sagaon M, Murata K, Hardacre JM, De Maio A, Talamini MA. CO2 Pneumoperitoneum modifies the inflammatory response to sepsis. Ann Surg. 2003 Mar; 237[3]:343-50. [DOI: 10.1097/01.SLA.0000055271. 58945.E2]

21. Lee FY, Leung KL, Lai PB, Lau JW. Selection of patients for laparoscopic repair of perforated peptic ulcer. Br J Surg. 2001 Jan;88[1]:133-6. [DOI: 10.1046/j.1365-2168.2001. 01642.x]. 